\title{
Large sample neutron activation analysis of a ceramic vase
}

\author{
I. E. Stamatelatos $\cdot$ F. Tzika $\cdot$ T. Vasilopoulou $\cdot$ \\ M. J. J. Koster-Ammerlaan
}

Received: 29 October 2009/Published online: 28 January 2010

(c) Akadémiai Kiadó, Budapest, Hungary 2010

\begin{abstract}
Large Sample Neutron Activation Analysis (LSNAA) was applied to perform non-destructive elemental analysis of a ceramic vase. Appropriate neutron self-shielding and gamma ray detection efficiency calibration factors were derived using Monte Carlo code MCNP5. The results of LSNAA were compared against Instrumental Neutron Activation Analysis (INAA) results and a satisfactory agreement between the two methods was observed. The ratio of derived concentrations between the two methods was within 0.7 and 1.3. Estimation of the activity level decay with time showed that the vase could be released from regulatory control at about 3 months postirradiation. This study provided an analytical procedure for bulk sample analysis of precious and archaeological objects that need to be preserved intact and cannot be damaged for sampling purposes.
\end{abstract}

Keywords Neutron activation analysis - Large sample · Gamma spectrometry

I. E. Stamatelatos $(\bowtie) \cdot$ F. Tzika $\cdot$ T. Vasilopoulou Institute of Nuclear Technology - Radiation Protection, NCSR 'Demokritos', 15310 Aghia Paraskevi, Greece e-mail: ion@ipta.demokritos.gr

T. Vasilopoulou

School of Applied Mathematical and Physical Science, National

Technical University of Athens, 15780 Athens, Greece

M. J. J. Koster-Ammerlaan

Reactor Institute Delft, Delft University of Technology,

2629JB Delft, The Netherlands

\section{Introduction}

Authenticity and provenance studies often require elemental analysis of artefacts and other findings. Instrumental Neutron Activation Analysis (INAA) is an established technique allowing such analysis to be performed [1]. The technique is based on neutron irradiation of samples obtained from the object of interest and measurement of the emitted gamma rays using a gamma spectrometer system. The mass of analyzed samples is in the range from milligrams to grams, representing a small portion of the bulk material. Nevertheless, there are applications where representative sampling from the bulk material cannot be performed. Large Sample Neutron Activation Analysis (LSNAA) enables non-destructive analysis of bulk samples and objects, up to several liters in volume, as a whole and therefore is a suitable technique for analysis of objects that cannot be damaged for sampling purposes [2].

In LSNAA the sample is irradiated at a research reactor graphite thermal neutron column and transferred to a gamma ray spectrometry system to be counted either as a whole [3] or using a scanning geometry counting configuration [4]. Corrections are required for self-shielding of the activating neutrons [5, 6], self-absorption of gamma rays [7], heterogeneity of the sample [8,9] and geometric factor during gamma counting [10]. Moreover, $\mathrm{k}_{0}$ based calibration techniques for LSNAA have been presented $[11,12]$.

In this work LSNAA was applied to perform nondestructive elemental analysis of a vase composed of ceramic material. Appropriate neutron self-shielding and gamma ray detection efficiency calibration factors were derived using the Monte Carlo method. The results of LSNAA were compared against conventional INAA results and a satisfactory agreement between the two methods was 
observed. This work provides a nuclear analytical procedure for bulk sample elemental analysis of precious and archaeological objects that need to be preserved intact.

\section{Experimental}

The analyzed item was a commercially purchased handmade ceramic vase shown in Fig. 1. The outer dimensions of the vase were $11.5 \mathrm{~cm}$ in diameter (at maximum) and $15.6 \mathrm{~cm}$ in height. The average wall thickness was $0.43 \mathrm{~cm}$ and its weight was $376 \mathrm{gr}$. It is noted that the external surface of the vase was painted by acrylic colors.

The experimental procedures were performed at the facilities of Reactor Institute Delft, Delft University of Technology (The Netherlands). Neutron irradiation was performed at the Big Sample Neutron Irradiation System (BISNIS) installed at Hoger Onderwijs Reactor graphite thermal neutron column [13]. BISNIS provides a moderated neutron flux of $5 \times 10^{8} \mathrm{~cm}^{-2} \cdot \mathrm{s}^{-1}$. The irradiation time was $12 \mathrm{~h}$. During irradiation eighteen zinc flux monitors were positioned on the surface of the sample. The monitors were removed after the end of irradiation and measured using a calibrated well type HPGe detector and 30 min counting time. The results were interpreted in terms of thermal neutron flux.

Measurements of emitted gamma rays from the vase were performed using a HPGe detector based spectrometry

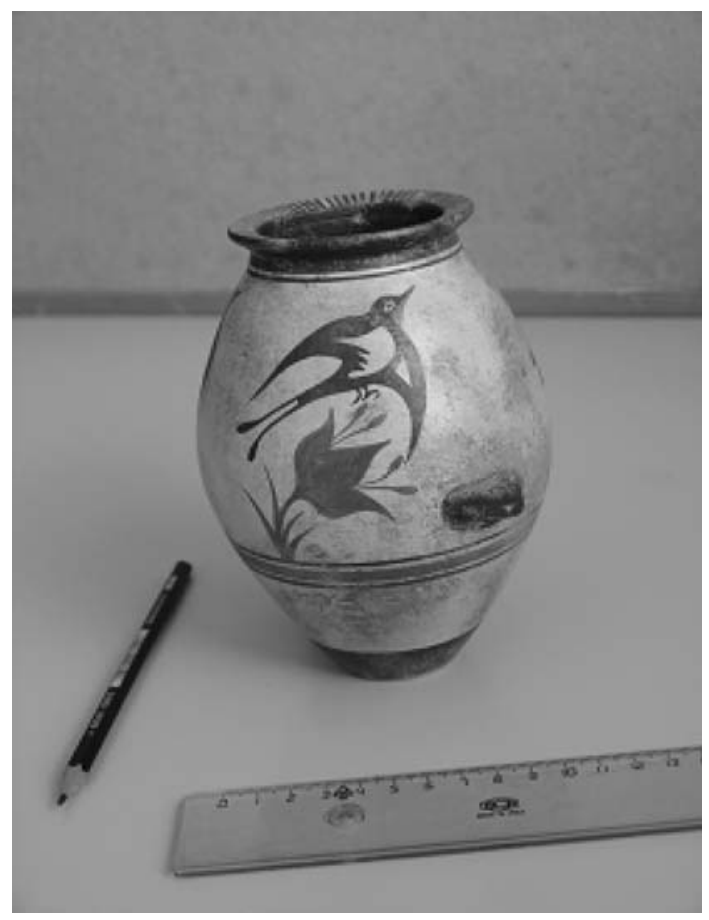

Fig. 1 Picture of the analyzed ceramic vase
Table 1 Isotopes, their half-lives and photon energies used for analysis

\begin{tabular}{llc}
\hline Product isotope & Half-life & Energy $(\mathrm{keV})$ \\
\hline${ }^{76} \mathrm{As}$ & $26.32 \mathrm{~h}$ & 657 \\
${ }^{47} \mathrm{Ca}$ & 4.54 days & 1297.1 \\
${ }^{141} \mathrm{Ce}$ & 32.5 days & 145.4 \\
${ }^{60} \mathrm{Co}$ & 5.27 years & 1332.5 \\
${ }^{51} \mathrm{Cr}$ & 27.7 days & 320 \\
${ }^{134} \mathrm{Cs}$ & 2.06 years & 795.8 \\
${ }^{152} \mathrm{Eu}$ & 13.33 years & 1408 \\
${ }^{59} \mathrm{Fe}$ & 44.5 days & 1099 \\
${ }^{140} \mathrm{La}$ & 40.28 h & 1596.1 \\
${ }^{86} \mathrm{Rb}$ & 18.66 days & 1076.6 \\
${ }^{122} \mathrm{Sb}$ & 2.7 days & 564 \\
${ }^{46} \mathrm{Sc}$ & 83.83 days & 889.3 \\
${ }^{153} \mathrm{Sm}$ & 46.7 h & 103.2 \\
${ }^{187} \mathrm{~W}$ & 23.9 h & 479.5 \\
${ }^{169} \mathrm{Yb}$ & 32.02 days & 198.0 \\
\hline
\end{tabular}

system. The gamma ray detection system is described in detail elsewhere [14]. The detector consisted of a HPGe crystal of $96 \%$ relative efficiency, $1.82 \mathrm{keV}$ energy resolution at the $1332 \mathrm{keV}{ }^{60} \mathrm{Co}$ photo-peak and peak to Compton ratio of 97:1. Activation gamma ray spectra were measured 5 days after irradiation for $3 \mathrm{~h}$. During measurement the vase was rotated around its vertical axis to minimize axial non-uniformity of activation. The distance from the detector surface to the axis of rotation was $20 \mathrm{~cm}$. The acquired activation spectrum was corrected with the corresponding gamma ray background spectrum. The isotopes, their half-lives and photon energies used for large sample analysis are shown in Table 1.

Following to LSNAA five sub-samples were randomly obtained from the vase material. The average weight of the sub-samples was $240 \mathrm{mg}$. These samples were analyzed by conventional "small sample" INAA. Irradiations were performed in polyethylene vials using zinc flux monitors in a thermal neutron flux of about $5 \times 10^{12} \mathrm{~cm}^{-2} \mathrm{~s}^{-1}$. The emitted gamma rays were measured approximately 6 and 19 days after irradiation. The quantification was carried out using zinc as the comparator element and the calibration constants determined at RID and on the basis of the $\mathrm{k}_{0}$ method [15].

\section{Monte Carlo simulations}

In order to obtain quantitative results from LSNAA the experimental data need to be evaluated for self-shielding of the activating neutrons, self-absorption of gamma rays and the geometric factor during gamma counting of the bulk 
sample. The Monte Carlo code MCNP, version 5 [16], was used in order to model the neutron irradiation and gamma counting configurations and derive the required LSNAA correction factors. Since these factors depend on the geometry and material of the sample, a close approximation of the vase was required. Moreover, the graphite pile, irradiation container and HPGe detector were modeled in detail. Cross section data from the Evaluated Nuclear Data File (ENDF) system were used [17]. MCNP code and cross section data packages were obtained from NEA Data Bank (France).

\section{Neutron irradiation model}

Simulations were performed assuming thermal neutrons incident on the surface of the graphite pile. Due to the high thermal to epithermal neutron flux ratio at BISNIS facility (of about 250), neutron moderation within the ceramic material is of minor importance and was not taken into account. Thermal fluxes were predicted using track length estimates of neutron flux, in units of $\mathrm{cm}^{-2}$ per source neutron. The neutron self-shielding correction factor, $f_{\mathrm{n}}$, was calculated as the ratio of the average predicted thermal neutron flux throughout the volume of the sample to the average predicted thermal neutron flux over the external surface of the vase. The activating neutron flux could be derived by combining the experimentally determined thermal neutron flux on the surface of the vase as measured by the zinc monitors and the MCNP predicted neutron selfshielding correction factor.

\section{Gamma ray detection model}

The HPGe detector full energy peak efficiency for the large sample was calculated using the efficiency transfer method on the basis of the full energy peak efficiency measured for a reference point source. This factor provides the difference in actual detector response for a given gamma ray energy compared to the detector response if the sample (vase) would have been a point-source located in a reference point without gamma attenuation and scattering. It has been shown that the full energy peak efficiency transfer method increases greatly the accuracy of the results of quantitative analysis by gamma spectrometry and avoids time consuming calibration sequences [18].

MCNP code was used to predict full energy peak efficiency for the reference point source at $20 \mathrm{~cm}$ distance from the detector (at the geometrical centre of the vase) and for the actual vase source configuration in order to derive the efficiency transfer factor. The MCNP gamma ray detector and vase geometry model is shown in Fig. 2.

Pulse height tally was used to predict the detector's response in terms of energy deposited in the active volume

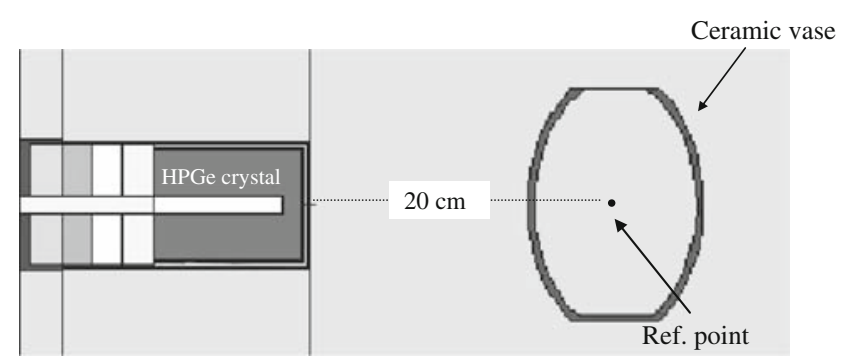

Fig. 2 Schematic representation of the HPGe detector and vase model

Table 2 Geometric characteristics of the simulated HPGe detector

\begin{tabular}{ll}
\hline Parameter & HPGe detector (mm) \\
\hline Crystal diameter (including dead layer) & 75.5 \\
Crystal length (including dead layer) & 97.1 \\
Dead layer thickness (top and side) & 0.7 \\
Hole diameter & 10.8 \\
Hole depth & 84.47 \\
Window diameter & 77.9 \\
Window thickness & 1 \\
Window material & $\mathrm{Al}$ \\
Crystal-to-window distance & 4 \\
\hline
\end{tabular}

of the crystal in the specified energy bin and thus estimate the absolute full energy peak efficiency of the detector. The geometrical characteristics of the detector used in the model are shown in Table 2. It is stressed that the detector active crystal volume was optimized on the basis of measured data using standard point sources and a set of MCNP calculations to adjust the thickness of the effective germanium crystal dead-layer and account for discrepancies between the nominal active volume and the actual one. This method has been applied by other workers developing HPGe models for efficiency calibration [19].

\section{Sample clearance}

An important parameter related to the application of LSNAA in cultural heritage, authentication and provenance studies is the time interval ("cooling time") required in order to exempt the large sample from the regulatory requirements of radioactive substances. The activity generated in the large sample depends on the cross section of each reaction, the neutron flux, the elemental concentration of the irradiated material and the irradiation time. After the end of irradiation, the total sample radioactivity decreases with time according to the decay scheme of each radionuclide. The sample can be released from regulatory control ("clearance") if its total activity as well as activity 
concentration per unit mass is below specific exemption limits. International Atomic Energy Agency [20] provided exemption values of activity and activity concentrations per radionuclide. In the case of a mixture of radio-nuclides the sample is considered cleared when the following criterion applies:

$\mathrm{A}=\Sigma_{\mathrm{i}}\left(\mathrm{A}_{\mathrm{i}} / \mathrm{A}_{\mathrm{r}, \mathrm{i}}\right)<1$

where $A_{i}$ is the activity concentration of the ith radionuclide in the sample, and $A_{r, i}$ is the exemption activity concentration of the ith radionuclide obtained from [20].

\section{Results and discussion}

Correction factors

Immersion of the large sample within the graphite pile resulted in a small perturbation of the thermal neutron field. The experimentally determined average thermal neutron flux at the surface of the vase was $(4.18 \pm$ $0.23) \times 10^{12} \mathrm{~cm}^{-2} \mathrm{~s}^{-1}$ as measured by the zinc foils $(n=18)$. The MCNP predicted thermal neutron selfshielding factor, $\mathrm{f}_{\mathrm{n}}$, was $0.981 \pm 0.015$. By applying this factor on the average thermal neutron flux over the surface of the vase, the average activating thermal neutron flux within its volume was $(4.10 \pm 0.24) \times 10^{12} \mathrm{~cm}^{-2} \mathrm{~s}^{-1}$.

The MCNP calculated full energy peak efficiency curves for the point and the actual "vase" shaped volume sources over the photon energy range from 50 to $1400 \mathrm{keV}$ are shown in Fig. 3. In this figure the resulting efficiency transfer function $\left(\mathrm{f}_{\gamma}\right)$, from point to "vase" source geometries, is also shown. From this figure it can be observed that $\mathrm{f}_{\gamma}$ increases with energy. For example, at $320 \mathrm{keV}\left({ }^{51} \mathrm{Cr}\right.$ peak), $604 \mathrm{keV}$ $\left({ }^{134} \mathrm{Cs}\right.$ peak $), 815 \mathrm{keV}\left({ }^{140} \mathrm{La} \mathrm{peak}\right), 1332 \mathrm{keV}\left({ }^{60} \mathrm{Co}\right.$ peak$)$, $\mathrm{f} \gamma$ factor has the value of $0.915 \pm 0.003,0.943 \pm 0.004$, $0.955 \pm 0.005,0.965 \pm 0.005$, respectively. This result is attributed to the decrease in photon attenuation within the ceramic material with increasing photon energy. We note that the reported uncertainty on the $\mathrm{f}_{\gamma}$ values is the statistical uncertainty of the calculation.

Combination of neutron and gamma ray correction factors yields an "overall correction factor" per given photon energy. The correction factor depends on material, size and shape of the large sample itself and is sample and facility specific. It is evident that for the ceramic vase discussed it is the gamma correction which is the significant. This result reflects the low thermal neutron attenuation properties of the ceramic material resulting in a calculated mean free path of thermal neutrons of $4 \mathrm{~cm}$ in the ceramic material which is an order of magnitude larger than the thickness of the vase wall $(0.43 \mathrm{~cm})$. Nevertheless, Stamatelatos and Tzika [21] calculated correction factors

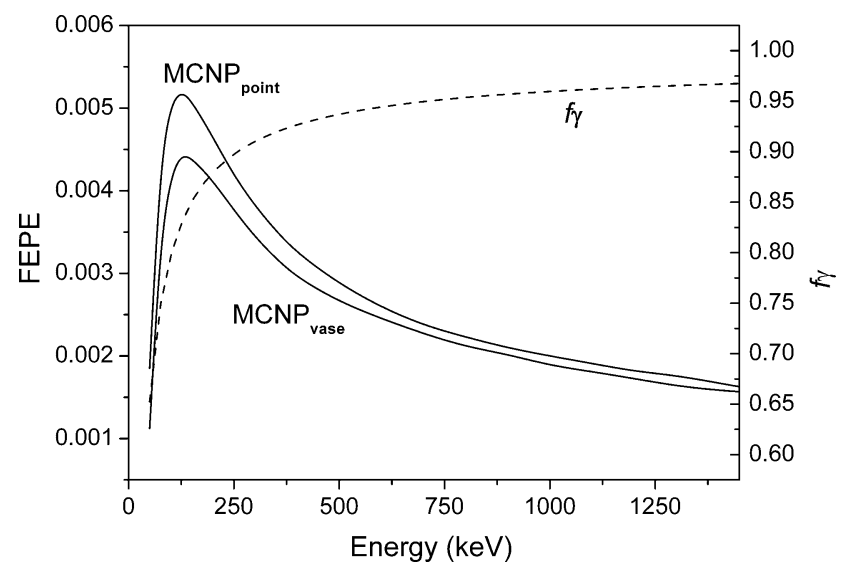

Fig. 3 Predicted Full Energy Peak Efficiency (FEPE) for the point and vase source and efficiency transfer factor $\left(\mathrm{f}_{\gamma}\right)$ as a function of photon energy

for neutron self-shielding, $\gamma$-ray attenuation and volume distribution of the activity in large volume ceramic samples of hollow cylindrical shape with wall thickness ranging up to $1.5 \mathrm{~cm}$.

\section{Elemental analysis}

Table 3 shows the elemental concentration results derived by LSNAA and INAA, the ratio of LSNAA to INAA elemental concentration and the limits of detection (LOD) [22] of the two techniques, respectively. The element concentration ratios were within 0.7 and 1.3 , for all elements. The LSNAA derived elemental concentrations for $\mathrm{Eu}, \mathrm{W}$ and $\mathrm{Yb}$ were close to the LOD for these elements. It is noted that LODs for LSNAA are higher than those of INAA, however this reflects the significantly lower integrated neutron flux on the sample during irradiation. Nevertheless, the results shown in Table 3 indicate a reasonably good agreement between concentrations found by large sample and small sample neutron activation analysis.

To further compare the results, Z-scores per element were calculated as the difference between the large sample and the small sample elemental concentration results, divided by the combined uncertainties of the two. Z-score values are then compared to determined classification being $|\mathrm{Z}| \leq 2$ considered satisfactory, $2<|\mathrm{Z}| \leq 3$ considered of questionable quality and $|Z|>3$ considered unsatisfactory. The Z-score results for the elements determined by the two methods are shown in Fig. 4. It can be observed that $\mathrm{Eu}, \mathrm{Fe}, \mathrm{Co}, \mathrm{W}, \mathrm{Ca}, \mathrm{Yb}, \mathrm{As}, \mathrm{Cs}, \mathrm{La}, \mathrm{Sb}, \mathrm{Rb}$ have $|z| \leq 2$, Ce, Cr, Sc have $2<|z| \leq 3$ and Sm has $|z|>3$.

The high Z-scores for $\mathrm{Sm}$ and $\mathrm{Ce}$ can be explained by the differences in elemental concentrations determined by the two techniques and the small uncertainty values. The elemental concentration differences can be taken to suggest that the gamma ray efficiency curve used for LSNAA may 
Table 3 Elemental concentrations, ratio of concentrations and limits of detection (LOD) for LSNAA and INAA

\begin{tabular}{|c|c|c|c|c|c|}
\hline Element & $\begin{array}{l}\text { Concentration LSNAA } \\
(\mathrm{mg} / \mathrm{kg})\end{array}$ & $\begin{array}{l}\text { Concentration INAA } \\
(\mathrm{mg} / \mathrm{kg})\end{array}$ & $\begin{array}{l}\text { Ratio LSNAA/ } \\
\text { INAA }\end{array}$ & $\begin{array}{l}\text { LOD (LSNAA) } \\
(\mathrm{mg} / \mathrm{kg})\end{array}$ & $\begin{array}{l}\text { LOD (INAA) } \\
(\mathrm{mg} / \mathrm{kg})\end{array}$ \\
\hline $\mathrm{Eu}$ & $0.80 \pm 0.19$ & $1.14 \pm 0.03$ & $0.70 \pm 0.17$ & 0.75 & 0.06 \\
\hline $\mathrm{Sm}$ & $3.61 \pm 0.23$ & $4.79 \pm 0.10$ & $0.75 \pm 0.05$ & 0.07 & 0.03 \\
\hline $\mathrm{Ce}$ & $40.00 \pm 4.57$ & $52.80 \pm 1.27$ & $0.76 \pm 0.09$ & 11.99 & 0.82 \\
\hline $\mathrm{Sc}$ & $17.48 \pm 0.95$ & $20.40 \pm 0.20$ & $0.86 \pm 0.05$ & 0.16 & 0.02 \\
\hline $\mathrm{Cr}$ & $397.84 \pm 22.76$ & $462.00 \pm 5.27$ & $0.86 \pm 0.05$ & 18.08 & 2.88 \\
\hline $\mathrm{Fe}$ & $49833.75 \pm 3361.34$ & $56300.00 \pm 585.52$ & $0.89 \pm 0.06$ & 1718.69 & 88.20 \\
\hline Co & $32.05 \pm 1.98$ & $35.80 \pm 0.42$ & $0.90 \pm 0.06$ & 2.49 & 0.24 \\
\hline W & $1.68 \pm 0.45$ & $1.76 \pm 0.22$ & $0.96 \pm 0.28$ & 1.05 & 0.99 \\
\hline $\mathrm{Ca}$ & $70039.44 \pm 10112.11$ & $71000.00 \pm 2272.00$ & $0.99 \pm 0.15$ & 13266.50 & 1880.00 \\
\hline $\mathrm{Yb}$ & $2.26 \pm 0.50$ & $2.29 \pm 0.06$ & $0.99 \pm 0.22$ & 1.79 & 0.15 \\
\hline As & $8.44 \pm 1.40$ & $8.36 \pm 0.28$ & $1.01 \pm 0.17$ & 5.73 & 0.54 \\
\hline Cs & $7.05 \pm 0.91$ & $6.84 \pm 0.18$ & $1.03 \pm 0.14$ & 2.83 & 0.39 \\
\hline $\mathrm{La}$ & $28.78 \pm 1.55$ & $27.40 \pm 0.27$ & $1.05 \pm 0.06$ & 0.12 & 0.09 \\
\hline $\mathrm{Sb}$ & $0.64 \pm 0.08$ & $0.53 \pm 0.04$ & $1.20 \pm 0.18$ & 0.20 & 0.14 \\
\hline $\mathrm{Rb}$ & $139.88 \pm 22.40$ & $110.00 \pm 2.20$ & $1.27 \pm 0.21$ & 52.73 & 4.40 \\
\hline
\end{tabular}

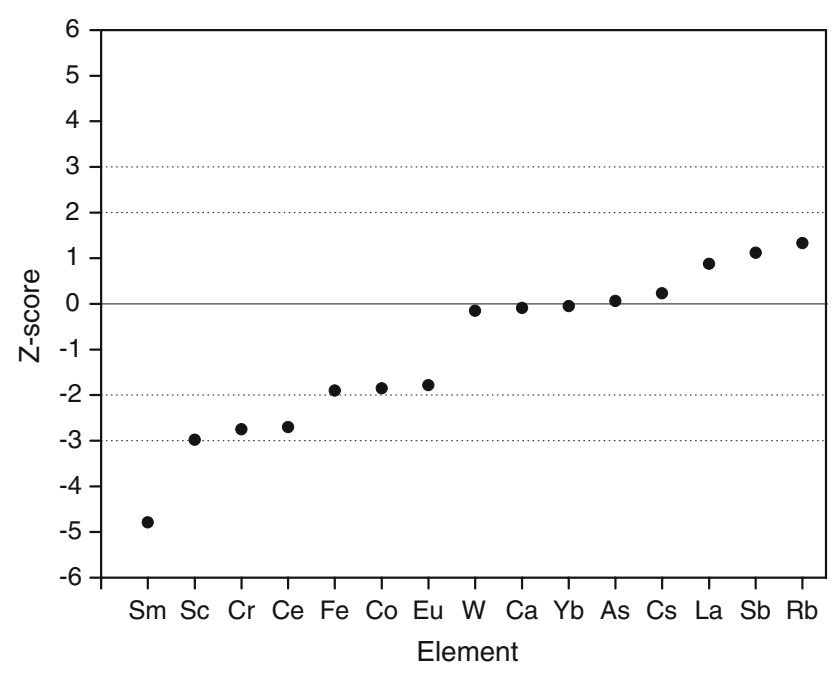

Fig. 4 Z-scores for the elemental concentration results

be inadequate at the lower photon energy region (i.e. below $150 \mathrm{keV}$ ), since $\mathrm{Sm}$ and Ce are determined by the photopeaks at 103.2 and $145.4 \mathrm{keV}$, respectively. Other potential sources of error are spectral interferences, differences in peak fitting, summing and counting geometry corrections.

\section{Sample clearance}

Figure 5 shows the calculated sum of activity concentration ratios, for all radionuclides in the sample, calculated by Eq. 1 as a function of cooling time (time after the end of irradiation). From this figure it can be observed that at 80 days post irradiation the calculated parameter $\mathrm{A}$ is less than one $(\sim 0.92)$ and the vase can be 'cleared' from regulatory

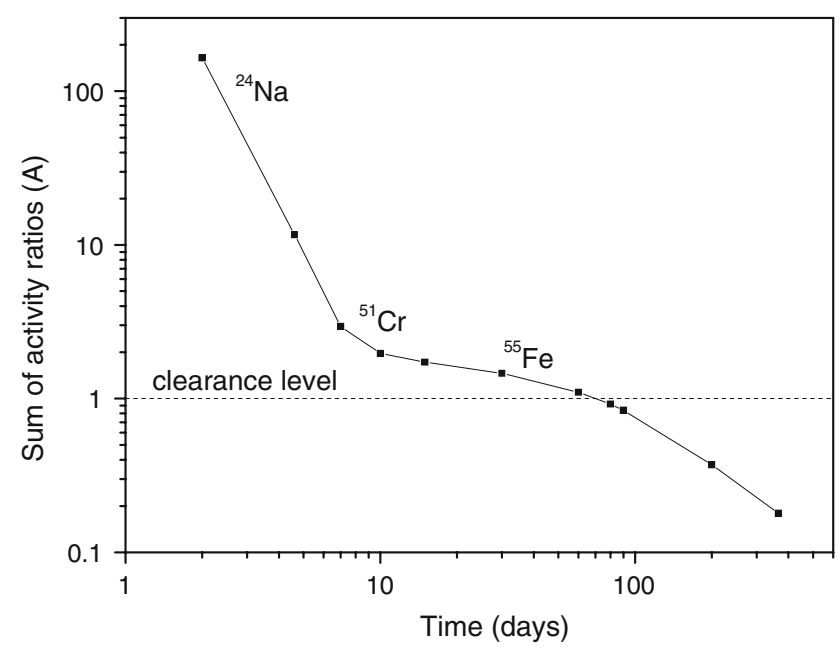

Fig. 5 Sum of activity concentration ratios (A) as a function of cooling time

control. Dominant nuclides were ${ }^{55} \mathrm{Fe}$ (half-time 2.74 years), ${ }^{46} \mathrm{Sc}$ (half-time 83.8 days), ${ }^{51} \mathrm{Cr}$ (half-time 27.7 days), ${ }^{59} \mathrm{Fe}$ (half-time 44.5 days), ${ }^{60} \mathrm{Co}$ (half-time 5.27 years) contributing $29,18,7,6,3 \%$ to the total radioactivity, respectively. Moreover, the contact gamma dose rate was estimated to be $0.18 \mu \mathrm{Sv} / \mathrm{h}$ level. One year (365 days) post irradiation the calculated parameter A was found to be 0.18 while the contribution of the dominant nuclides ${ }^{55} \mathrm{Fe},{ }^{60} \mathrm{Co},{ }^{46} \mathrm{Sc},{ }^{152} \mathrm{Eu}$ and ${ }^{134} \mathrm{Cs}$ to the total activity was $58,6,4,2$ and $1 \%$, respectively. At that time, the total activity of the vase was $5.11 \mathrm{E}+3 \mathrm{~Bq}$ and moreover, the contact gamma dose rate was estimated to be $0.08 \mu \mathrm{Sv} / \mathrm{h}$. It is noted that the dominant nuclide ${ }^{55} \mathrm{Fe}$ is not a gamma ray emitter and therefore it does not contribute to the gamma dose rate. 


\section{Conclusions}

In this work a ceramic vase was analyzed by LSNAA and the results of the analysis were compared to results obtained by INAA. The required corrections for thermal neutron self-shielding during sample irradiation and $\gamma$-ray detection efficiency for the volume source during counting were derived using the Monte Carlo method enabling precise simulation of the complex large sample, irradiation facility and gamma ray detector configurations. A satisfactory agreement between LSNAA and INAA results was observed within the range of $0.7-1.3$. The activity induced in the object was low enough to enable release from regulatory control in a relatively short time period of about 3 months post neutron irradiation.

The results of this study demonstrated the feasibility of performing LSNAA to a ceramic vase (as a whole) and therefore contribute to the requirement for developing validated nuclear analytical procedures for non-destructive, multi-element bulk sample analysis of precious and archaeological objects that need to be preserved intact and cannot be damaged for sampling purposes. Moreover, LSNAA is not affected by post-depositional elemental alterations [23] since the analytical information is provided from the whole of the bulk material and not from the surface layers of the material only. For comparison, other established non-destructive analytical methods such as $\mathrm{X}$-ray fluorescence analysis or analytical techniques based on charged particle irradiation (PIXE) can only analyze superficial layers of the sample.

Acknowledgements The useful discussions with Dr. P. Bode and Dr. M. Blaauw at RID are most gratefully acknowledged. This research project has been supported by the European Commission under the sixth Framework Programme through the Key Action: Strengthening the European Research Area, Research Infrastructures, contract no. RII3-CT-2003-505925.

\section{References}

1. Speakman RJ, Glascock MD (2007) Acknowledging fifty years of neutron activation analysis in archaeology. Archaeometry 49:179-183

2. International Atomic Energy Agency (2005) Report of the technical meeting on 'large sample neutron activation analysis using low flux irradiation facilities', IAEA, Vienna, Austria, 7-11 Nov 2005

3. Overwater RMW, Bode P, De Goeij JJM, Hoogenboom JE (1996) Feasibility of elemental analysis of kilogram-size samples by instrumental neutron activation analysis. Anal Chem 68:341-348

4. Blaauw M, Baas HW, Donze M (2003) Height-resolved largesample INAA of a $1 \mathrm{~m}$ long, $13 \mathrm{~cm}$ diameter ditch-bottom sample. Nucl Instrum Methods Phys Res A 505:512-516
5. Tzika F, Stamatelatos IE (2004) Thermal neutron self-shielding correction factors for large sample neutron activation analysis using the MCNP code. Nucl Instrum Methods Phys Res B 213: 177-181

6. Degenaar IH, Blaauw M, De Goeij JJM (2003) Correction for neutron self-shielding in large-sample prompt-gamma neutron activation analysis. J Radioanal Nucl Chem 257:467-470

7. Tzika F, Stamatelatos IE, Kalef-Ezra J, Bode P (2004) Large sample neutron activation analysis: correction for neutron and gamma attenuation. Nukleonika 49:115-121

8. Overwater RMW, Bode P (1998) Computer simulations of the effects of inhomogeneities on the accuracy of large sample INAA. Appl Radiat Isot 49:967-976

9. Tzika F, Stamatelatos IE, Kalef-Ezra J (2007) Neutron activation analysis of large volume samples: the influence of inhomogeneity. J Radioanal Nucl Chem 271:233-240

10. Overwater RMW, Bode P, De Goeij JJM (1993) Gamma-ray spectroscopy of voluminous sources: corrections for source geometry and self-attenuation. Nucl Instrum Methods Phys Res A 324:209-218

11. Blaaw M (1997) The $\mathrm{k}_{0}$ calibration of the IRI system for INAA of samples in the kg range. J Radioanal Nucl Chem 220:233-235

12. Nair AGC, Acharya R, Sudarshan K, Gangotra S, Reddy AVR, Manohar SB, Goswami A (2003) Development of an internal monostandard instrumental neutron activation analysis method based on in situ detection efficiency for analysis of large nonstandard geometry samples. Anal Chem 75:4868-4874

13. Overwater RMW, Hoogenboom JE (1994) Accounting for the thermal neutron flux depression in voluminous samples for instrumental neutron activation analysis. Nucl Sci Eng 117:141-157

14. Bode P, Overwater RMW, De Goeij JJM (1997) Large sample neutron activation analysis: present status and prospects. J Radioanal Nucl Chem 216:5-11

15. Blaauw $M$ (1996) The $\mathrm{k}_{0}$-consistent IRI $\gamma$-ray catalogue for INAA, IRI. Delft, The Netherlands

16. X-5 Monte Carlo Team (2003) MCNP - a general Monte Carlo N-particle transport code, Version 5, LA-UR-03-1987, Apr 2003

17. Rose PF (1991) Compiler and editor, ENDF-201, ENDF/B-VI summary documentation, BNL-NCS-17541. Brookhaven National Laboratory, New York

18. Piton F, Lepy MC, Be MM, Plagnard J (2000) Efficiency transfer and coincidence summing corrections for $\gamma$-ray spectrometry. Appl Radiat Isot 52:791-795

19. Ródenas J, Pascual A, Zarza I, Serradell V, Ortiz J, Ballesteros L (2003) Analysis of the influence of germanium dead layer on detector calibration simulation for environmental radioactive samples using the Monte Carlo method. Nucl Instrum Methods Phys Res A 496:390-399

20. International Atomic Energy Agency (1996) International basic safety standards for protection against ionizing radiation and for the safety of radiation sources, safety series no. 115, IAEA Vienna

21. Stamatelatos IE, Tzika F (2007) Large sample neutron activation analysis: a challenge in cultural heritage studies. Annali di Chimica 97:505-512

22. Currie LA (1968) Limits for qualitative detection and quantitative determination. Anal Chem 40:586

23. Schwedt A, Momusen H, Zacharias N (2004) Post-depositional elemental alterations in pottery: Neutron activation analysis of surface and core samples. Archaeometry 46:85-101 